\title{
The Influence of Interactions Between Offspring Successors and Other Factors Have on Their Succession Intention in Family Business
}

\author{
Xuefang Liu, Yuewen Wang, Fenglian Li, Lili Pan \\ Qilu University of Technology \\ Jinan, China \\ xfliuhr@sina.com
}

\author{
Ningyu Tang \\ Shanghai Jiaotong University \\ Shanghai, China \\ nytang@sjtu.edu.cn
}

\begin{abstract}
The offspring's positive feelings to family business and the ability or confidence to manage family business are usually cultivated through the interaction of several factors, especially interaction among the individual, the family and the enterprise. These positive feelings, the ability and confidence have direct influence on the succession intention. This thesis firstly introduces the interaction modes between the successor and the family, the enterprise and the society as independent variables influencing the family business offspring's succession intention. It also introduces the succession commitment, which reflects the emotional factors, and the self-efficacy which reflects the confidence and ability, as the mediators. A series of propositions have been given. This paper will contribute to better understanding the forming of the offspring's succession intention.
\end{abstract}

Keywords-family business; succession intention; influential factors; functioning mechanism; the viewpoint of interaction

\section{INTRODUCTION}

Most family business owners wish the next generation would take over their firms (Mohamad \& Yahya, 2010), while, being a striking contrast, only $16 \%$ of their kids would like to, making up only $1 / 3$ of the samples with a clear intention (The family business research group of Chinese civilian (private) economy seminar, 2011). The past researches on the succession intention of the business owners' offspring also reveals that only $1 / 3$ of the research samples have clear intention to succeed (Stavrou \& Winslow, 1996; Wang \& Jia, 2005).

Tan (2008) discovers that the offspring's succession situation in reality does not coincide with their intentions. Only $24.24 \%$ are willing to enter the enterprise after the graduation, while in reality it is $60.61 \%$. That is to say, $36 \%$ of the offspring do not want to take the succession at first but finally are forced or change their original ideas to take the succession and enter the enterprise.

If the offspring who are lack of succession intention are forced to take over the enterprise, it is easy for them to be dissatisfied with the enterprise and the family, and they usually take some radical reforms inside the enterprise after the succession (Farhi, 1990). This will greatly decrease the successful possibility of a succession (Goldberg \& Wooldridge, 1993). The research of Van der Merwe (2011) discovers that the young generation's willingness to stay in the family business will obviously influence the adaptability and the performance of the succession.

The failures of many family businesses are very shocking to the economy, the employment and the society. Thus, to understand the influential factors of the offspring's succession intention and take effective measures to improve the intention become very urgent tasks for the family businesses facing the succession problem( Jia, Dou, \& Wang, 2010), which is also a practical problem to the nation and the society. The contribution of this paper is to give a new view on the factors influencing the family businesses' offspring's succession intention.

\section{LITERATURE REVIEW}

There is still little understanding about the factors influencing the offspring's succession intention inside the family business (Zellweger, Sieger, \& Halter, 2011). The theory of planned behavior (Fishbein \& Ajzen, 1975) says that intention is the sign that how much effort people would like and plan to make to conduct the behavior. So offspring's succession intention within family business should be defined as: the sign that how much effort the family business offspring would like and plan to make to take over and manage the family business.

After summarizing the past scattered researches, Stavrou \& Swiercz (1998) puts forward a frame system including four dimensions which influence the offspring's succession intention and their working in the business: individual (related to personal demands, targets , abilities and interests), family (related to family members, family values and family demands), enterprise and market (the job opportunities in the market). They list many potential influential factors under each dimension and does some empirical studies. Griffeth, Allen, and Barrett (2006) put forward the four dimensions influencing the successor's resign from family business: the parent-successor relationship, the family relationship, the successor features and the enterprise features. By combining the four dimensions, the individual life cycle and the employee's resign model, they develop a process model to retain the successor inside family business. They firstly introduce the commitment, satisfaction and integration as the mediators between the resigning factors and the retaining 
intentions. Unfortunately the model has not been tested empirically.

The enterprise scale is usually regarded as an important factor influencing the succession intention. Stavrou's research (1999) reveals that the bigger the enterprise scale is, the more willing the offspring are to take over the family business. However, some researchers also say that the relation between the enterprise scale and the succession intention is not clear.

Rastogi and Agrawal (2010) study family business offspring in India, mostly 20-30 year old youngsters, and discover that the successor's intention to join the family business are influenced by factors such as the family pressure (positive), self-esteem( negative), the attitude toward work (positive), leadership (positive), the attitude toward risk (negative) and independence (negative). Education level (negative) and sex also have clear influence on the intention to join the family business. Males are more willing to join the parents' enterprise than females (Lansberg, 1991; Stavrou, 1999). Daughters are unwilling to seek a position in the family business because of traditions (Lansberg, 1991; Stavrou, 1999). Dumas's research (1992) also reveals that generally daughters won't be considered to participate in the family business management, unless there are no other choices. Different gender consciousness makes males more responsible than females in joining the enterprise and inheriting the family business. Daughters are more likely to start their business outside than being successors (Schroder, Schmitt-Rodermund, \& Arnaud, 2011).

Reiter (2010) researches the relationship between the communication frequency about the succession inside the family and the identical succession tendency of parents and offspring. Schröder, Schmitt-Rodermund, \& Arnaud (2011) examine employment intentions of the family business offspring in Germany, who are in their adolescence and discovers that among the big five personality traits: high openness can predict offspring's starting a business (offspring who intends to succeed or be an external employee show comparatively low openness); agreeableness and being an external employee are clearly positive correlated. Other traits show no clear difference.

Some experts point out that offspring's joining the family business is related to the birth order in the family (Aleorn, 1982; Godberg \& Woodride, 1993; Landsberg, 1991). Lansberg (1991) believes that the first kid is more likely to follow the parents' will to join the family business. However, Stavrou's research (1999) reveals that the children's birth order has nothing to do with the succession intention.

Zellweger, Sieger, \& Halter (2011) research the differences in intending to be an entrepreneur, a successor or an external employee caused by the control point, entrepreneurial selfefficacy, independence and innovative motives of students who have a family business background. He discovers that the intention of starting one's own business and the intention of succession show little difference in control point while high level of inner control leads to the intention of external employment. The high, medium, low levels of entrepreneurial self-efficacy and independent motives correspond respectively with working externally, interal succession and external employment. Students with high level of innovative motives prefer to start their business outside rather than take the succession.

Chlosta, Patzelt, Klein and Dormann (2012) find that not only parents' role models have strong influence on offspring's self-employment, but also the openness level of the offspring's personalities decides the influence. The higher openness level the offspring has, the less influence the parents' role models have on offspring's self-employment. On the contrary, the lower openness level the offspring has, the more influence it has. The self-employment here does not distinguish starting one's own business externally from internal succession.

China's researches on family business start a little later. The related researches begin to increase rapidly since 2001, but researches on family business succession are fewer (Yu, 2008). The present researches on family business succession in China mainly focus on the succession policies from the perspective of entrepreneurs. Only a few take the offspring as the subject to study and analyze. Zhang (2008) finds that personal interests, parents' expectation, the enterprise's advantages and guarantee, and the pressure to start an undertaking in the job market have positive influence on offspring's succession intention, while the offspring's external interests and opportunities have negative influence.

According to the research on 67 university students aged 18 to 28 years old, all of whom are offspring of family businesses in Wenzhou, $\mathrm{Yu}$ (2008) divides the potential factors influencing the offspring's succession intention of family business into 6 dimensions: internal occupation interests, external entrepreneur spirit, job market pressure, the material and spiritual guarantee, the pessimistic forecast of the enterprise's future, and the family business enterprise's superiority. He finds that only internal occupation interests have significant predicting effect to the enterprise's offspring's succession intention.

Jia, Dou and Wang (2010) discover that the need of self fulfillment and the development expectation of the family business have positive influence on the offspring's succession intention while personal targets, job understanding, the need of self development, the sense of family responsibility and the understanding of succession intention have no obvious influence. The Family Business Research Group of Chinese Civilian (Private) Economy Seminar (2011) discovers that the enterprise's industry is a very significant factor influencing the succession intention. And the enterprise owner's view of family control and the board setting are positive-correlated with the offspring's succession intention closely. Fang (2013) finds that the personal situation of the successor, the attitude of the incumbent to the succession, succession structure, family business status, industry status and macroeconomics status all have influence to offspring's succession intention.

Summarizing all the related researches on offspring's succession intention within family business, the following shortcomings exist: 1) The present few researches are mainly about the independent, separate, static influence on the succession intention from the aspects of individuals, enterprises, families, markets and relations, but not about the influence of the interactions between factors, such as the interaction 
between the successor and the family, the successor and the market. This makes the explanation of forming the succession intention inadequate. 2) Most of the past researches are to inspect the direct influence of the individual, the enterprise, the family and the market on succession intention. Few are about the mechanism of these factors influencing the succession intention, so they are weak in interfering and guiding the offspring's succession intention of family business.

This study tries to make some valuable attempts on these shortcomings. According to general system theory (Miller \& Rice, 1967; Rice, 1969), the connection modes between subsystems are critical to understanding the function of the whole system. The mode, quality and frequency of the interaction between the successor and the enterprise, the family and the society should have significant influence on the emotion of the successor and its confidence to manage to family business. Thus, to research on the influence of interaction modes on succession intention from the interaction view should be better to explain the formation mechanism and influential factors of the offspring's succession intention within the family business. Furthermore, the introduction of the succession commitment (which reflects the successor's emotion to the family business, responsibility and reliance) and the self-efficacy (which reflects the confidence and ability to manage the family business) as two mediators, can see better the influential mechanism of all these factors on succession intention.

\section{THE INTERACTION MODEL CONSTRUCTION OF OFFSPRING'S SUCCESSION INTENTION}

This study will inherit the idea of researching from the aspects of the individual, the family, the enterprise and the relationship. The difference is that this study will research from the aspect of the interaction between related factors. Human beings change situations and are changed by them. The interaction psychology emphasizes continuous, multidirectional interaction between person and situation characteristics. It believes that the situation will change in hints, returns and opportunities, while human will change in cognition, ability and motivation. The actual behavior is a function of continuous reaction and feedback between the person and the situation he faces (Terborg, 1981). The improvements of the successor's abilities, the generation of emotions all occur during the interaction of these factors. This study believes that the interaction mode among these factors and the interaction quality are key factors influencing the offspring's succession intention, so this study goes a step further to analyze the influence mechanism of the interaction on succession intention. According to the past materials, this study believes that the influence of these interactions on succession intention is mediated by the offspring's succession commitment to the family business, the entrepreneurial self-efficacy and administrative self-efficacy. The interaction model of succession intention influential factors is shown in fig.1. The connection part linked by bold black solid arrows is the diagram of the theoretical model of planned behavior (Duan, \& Jiang, 2008).

\section{A. The construction of the interaction modes among successors, families, firms and society}

Up to now, among family business succession research literature, only two articles mentioning the interaction between the successor and related factors are found. Cory's research (1990) reveals that the offspring's intention to join the family business is actually formed during the process of their growing up as teenagers. During their interaction with parents and the enterprise, they establish the concepts of parents and enterprise. Bracci and Vagnoni (2011) believe that the process of family business succession is the process of knowledge transferring, which is finished through the interaction among the present leader, the successor and the organization. These two articles put forward a concept of interaction but do not conduct a detailed study on the interaction modes. This study researches on the concrete interaction modes between the successor and the factors, the influence and functioning mechanism of different models' interaction to succession intention, hoping to spur further understanding of the process, features and outcome variables in the process of successors' growth and cultivation.

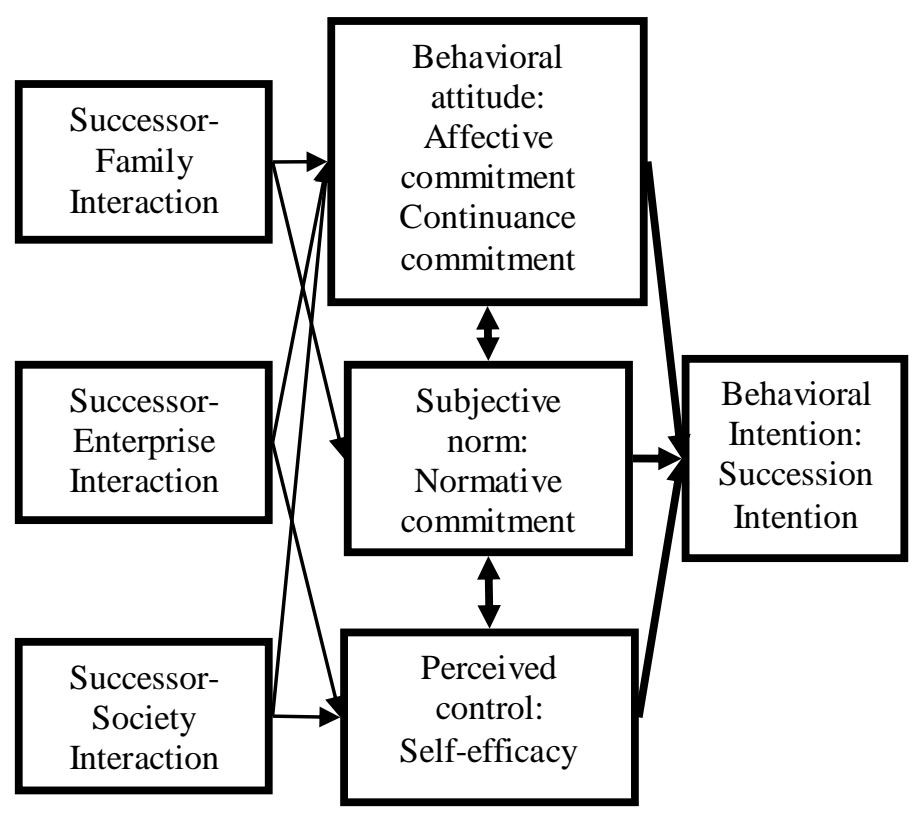

FIGURE 1 THE MODEL THAT THE INTERACTION BETWEEN SUCCESSOR AND ENVIRONMENT INFLUENCE

Handler (1989) puts forward three postures to authorities: conforming, rebellious and situational postures. Facing different situations and different objects, the successor's mentalities can directly influence the interaction mode with the object. So referring to the theory of Handler(1989), this study constructs the interaction modes when successors face different situations and different objects. Meanwhile, Handler (1989) puts forward three postures, all of which are comparatively positive to authentic behaviors or orders. This study believes that in reality there is also a posture that it is negative and indifferent to authority, which is named alienation posture here. 
Based on the above theory, this study constructs the concrete interaction mode between successor and all factors as follows:

1) The successor-enterprise interaction: mainly the successor's participation in policy-making and implementation of working tasks. The interaction modes include passive obedience (corresponding to the conforming type), equal participation (corresponding to the situational posture), arrogant and autocratic (based on the successor's status and situation in the family business, corresponding to the rebellious posture), and alienation types (lack of enthusiasm and be indifferent to the family business, corresponding to the alienation posture).

2) The successor-family interaction: mainly the modes of successor's participating in policy-making inside the family and task implementation. The interaction modes include passive obedience, equal participation, rebellion, and alienation types.

3) The successor-society interaction: Successor-society interaction is different from the successor-family interaction and the successor-enterprise interaction. The former pays more attention to understanding, exploring, grasping, adapting and reforming society, while the latter pays more attention to the relation handling among people. So the successor-society interaction can be divided into two types: the active participating type and the passive retreating type. The active participating type means participate actively in the social activities outside the family business, such as seeking external work experience, accepting formal education, exploring the outside social activity regulations. The passive retreating type is just the opposite.

Different interaction modes lead to different results, which are shown in cognitive appraisal, affective response, and intrinsic motivation (Cox, 1982, C.F. Robinson \& Thomas, 2007).

\section{B. The influence and functioning mechanism of interaction modes on succession intention.}

To research on the influence and functioning mechanism of interaction between the successor and related factors on succession intention, this study takes the theory of planned behavior as the research framework and introduces the succession commitment and self-efficacy as the mediators.

The theory of planned behavior (Ajzen, 1991) is the most famous attitude-behavior relation theory in social psychology. It believes that behavior intention is the most direct factor influencing the behavior. On the other hand, behavior intention is affected by personal attitude, the perception of social regulations and the perception of power to control behavior.

Organizational commitment is a very important concept in the field of organizational behavior and human resource (Ma, Kong, \& Sun, 2010), which is usually defined referring to the retaining and resigning of employees. Becker (1960) defines the organizational commitment as the psychological phenomenon of employees' wishing to stay in the organization after they invest more and more time, energy and emotion.
Organizational commitment is commonly regarded as a multidimensional concept. The most widely used one is the threedimensional model put forward by Allen and Meyer (1990). It contains affective commitment, continuance commitment and normative commitment. Affective commitment means the emotional reliance, recognition and efforts made by the members of the organization. Continuance commitment means the awareness of the instant and potential cost if the member leaves the organization. Normative commitment means the member's sense of social responsibility and obligation to stay in the organization cultivated under the influence of society.

Succession commitment can be regarded as a special form of organizational commitment. According to definitions of organizational commitment, the succession commitment can be defined as the emotional recognition and interest reliance the successor has on the family business and its values, or the volitional bond reflecting the responsibility to manage the family business and willingness to dedications. Based on the theory of organizational behavior, Sharma and Irving (2005) put forward the four-dimension model of family business succession commitment: affective, normative, calculative (the calculation of costs), and imperative (lack of job opportunities outside). This study will research on successor's succession commitment on the three-dimension organizational commitment model of Allen and Meyer (1990).

Self-efficacy is the faith that one can successfully accomplish certain tasks. It affects how people feel, think, and spur themselves and how people take action (Bandura, 1993). Sardeshmukh \& Corbett (2011) believes that senior executives play the role of managers as well as entrepreneurs. So this study needs to inspect the successor's entrepreneurial selfefficacy and administrative self-efficacy. The entrepreneurial self-efficacy is the confidence one owns that he/she can succeed in starting a business and finishing tasks (Hmieleski \& Corbett, 2008). Administrative self-efficacy is the confidence level that one has to succeed in managing position (Vianen, 1999).

Affective commitment and continuance commitment correspond with the attitude towards action in planned behavior, while normative commitment corresponds with the cognitive norms, and entrepreneurial self-efficacy and administrative self-efficacy correspond with the cognitive control of behavior. They should have strong prediction to succession intention. The successor's emotions to the enterprise, its confidence and ability to take over and manage the enterprise are all developed from the interaction between the successor and the enterprise, the family, the individual and the society. So the interaction between the successor and the family, the enterprise, and the society can predict the succession commitment, entrepreneurial self-efficacy and administrative self-efficacy. Thus, this study introduces the succession commitment, entrepreneurial selfefficacy and administrative self-efficacy as the mediators among the interaction modes between successor and all other factors, and succession intention.

1) The influence of successor-enterprise interaction mode: The four modes of successor-enterprise interaction have influence on succession intention. The passive obedience and alienation types are hard for the successor to get pleasure from 
the interaction, to get exercises from the policy-making, and to improve the management skill. Thus its succession intention will be comparatively low. The equal participation type can enable the successor to feel the fun of participation and the value of his life. Through participating in decision-making and work experience, the successor's abilities are improved, and the successor's succession intention will be high. The arrogant and autocratic type can enable the successor to get satisfaction and sense of worth from work, while the improvement of the decision-making and work abilities is comparatively low, so the succession intention will be in medium level. The influence of successor-enterprise interaction mode on succession intention will be mediated by the successor's affective commitment to the enterprise as well as by the entrepreneurial self-efficacy and administrative self-efficacy.

Accordingly this study makes the following propositions:

Proposition 1: The passive obedience and alienation types of successor-enterprise interaction mode have significant negative influence on succession intention.

Proposition 2: The equal participation type of the successorenterprise interaction mode has significant positive influence on succession intention.

Proposition 3: The arrogant and autocratic type of the successor-enterprise interaction mode has medium positive influence on succession intention.

Proposition 4: The influence of successor-enterprise interaction mode on succession intention will be mediated by the successor's affective commitment to the enterprise as well as by the entrepreneurial self-efficacy and administrative selfefficacy.

2) The influence of the successor-family interaction mode on succession intention: The four modes of successor-family interaction have influence on succession intention. The passive obedience, rebellion, and alienation types are difficult to cultivate intimate relations among family members and difficult to cultivate true feelings to the family business. Because the successor lacks of deep feelings to the family, he will be indifferent to the succession demands. So the succession intention will be low. The equal participation type of the successor-family interaction mode will be easy to develop deep feelings because of the close interaction and equal treatment among family members. If the family holds high expectation on the succession of family business, the successor will take it seriously. So the succession intention will be high. The successor-family interaction modes are mediated by the affective and normative commitment.

Accordingly this study makes the following Propositions:

Proposition 5: The passive obedience, rebellion, and alienation types of the successor-family interaction mode have significant negative influence on succession intention.

Proposition 6: The equal participation type of the successorfamily interaction mode has significant positive influence on succession intention.
Proposition 7: The successor-family interaction modes are mediated by the affective and normative commitment.

3) The influence of successor-society interaction mode on succession intention: The successor-family interaction modes have influence on succession intention. The active participating type means participating actively in the social activities outside the family business, such as seeking external work experience, accepting formal education, and actively paying attention to the changes and opportunities of the outside world. On one hand, this will improve the successor's opportunities and abilities if he wants to find a job outside. This decreases the cost-profit ratio if the successor gives up the succession, thus leading to lower succession intention. On the other hand, this will improve the successor's abilities to grasp the environment changes and opportunities, which will increase entrepreneurial self-efficacy, thus having positive influence on succession intention.

The passive retreating type is just the opposite. It means the successor does not seek external education and work opportunities, and he is indifferent to outside environment changes and opportunities. On the one hand, this will improve the difficulty and cost for his getting external jobs, which will improve the continuance commitment, thus leading to higher succession intention to manage the family business. On the other hand, this will decrease the entrepreneurial self-efficacy, leading to lower succession intention.

Accordingly this study makes the following Propositions:

Proposition 8: The active participating type of the successor-society interaction mode can reduce the succession intention by reducing the continuance commitment, and increasing the succession intention by increasing entrepreneurial self-efficacy.

Proposition 9: The passive retreating type of successorsociety interaction mode can increase the succession intention by increasing the continuance commitment, and reduce the succession intention by reducing entrepreneurial self-efficacy.

\section{CONCLUSION AND PROSPECT}

\section{A. Conclusion}

This study takes the theory of planned behavior as its research framework and introduces the succession commitment and self-efficacy as two mediators. From the viewpoint of interaction, this study researches the influence and functional mechanism on succession intention of the interactions between the successor and the family, the enterprise and the society. Integrating the whole research, this study establishes the interaction model of offspring's succession intention within family business. The innovations in this article are shown in two aspects: firstly, from the viewpoint of interaction, this study researches on the factors influencing the formation of offspring's succession intention within the family business. Based on the theory of Handler (1989), this study establishes the interaction mode between the successor and the family, the enterprise and the society and use different variables in different interaction modes to predict the successor's 
succession intention, which is beneficial to enrich the theories of family business succession and human resource development. Secondly, this study introduces the succession commitment and self-efficacy as the mediators of the relations between the succession intention and the influential factors, which offers better sight of the influential mechanism of all factors on succession intention.

\section{B. Prospect}

The weakness of this article is that it does not have empirical test, which is the direction the future research should focus on. There are still many details to accomplish, such as defining the interaction modes between the successor and the family, the enterprise and the society, the compiling of measurement questionnaires and the succession commitment questionnaires.

Besides, the objects of past researches on offspring's succession intention within family business are mostly school youngsters under 28 years old. The future research should expand the research objects to family business owners' offspring who are beyond 18 years old, studying or working. For the successful succession of family business, it is of great significance to research on the formation of the offspring's succession intention within family business, especially those who are employed full-time in family businesses or succeed the family businesses already, but in fact are unwilling to join the family businesses.

\section{ACKNOWLEDGMENT}

This paper is a result of the Research Base of Regional Innovation and Sustainable Development of Shandong Province.

\section{REFERENCES}

[1] Bracci, E. \& Vagnoni, E. Understanding small family business succession in a knowledge management perspective, The IUP Journal of Knowledge Management, 2011, IX(1): 7-36, Available at SSRN: http://ssrn.com/abstract=1776593.

[2] Chlosta, S., Patzelt, H., Klein, S.B., \& Dormann, C. Parental role models and the decision to become self-employed: The moderating effect of personality, Small Bus Econ, 2012, 38:121-138.

[3] Duan, W.T., \& Jiang, G.R. The review of the planned behavior theory (In Chinese), The Development of the Psychology Science, 2008, 16 (2):315-320
[4] Fang, Y. J., The Empirical Study on Family business Successor's Inheritance Intention(In Chinese), Master Dissertation of Donghua University, 2013.

[5] Griffeth, R.W., Allen, D.G., Barrett, R. Integration of family-owned business succession with turnover and life cycle models: Development of a successor retention process model, Human Resource Management Review, 2006, 16: 490-507.

[6] Handler W. C. Methodological issues and considerations in studying family businesses [J]. Family Business Review, 1989,2:257-276.

[7] Jia, S.H., Dou, J.S., \& Wang, X.T. The research on the transition between generations in family businesses-Based on the process view(In Chinese), Beijing: Science Press, 2010.

[8] Ma, F., Kong, F.J., \& Sun, H.L. The review on the organizational commitment, Information Science(In Chinese), 2010, 28(11):1741-1745.

[9] Mohamad, N., \& Yahya, S. Exploring succession planning within small family owned businesses, Japanese Journal of Administrative Science, 2010, 23(3): 177-191.

[10] Robinson, C.H., \& Thomas, S.P. The interaction model of client health behavior as a conceptual guide in the explanation of children's health behaviors, Public Health Nursing, 2004, 21(1/2):73-84.

[11] Sardeshmukh, S.R., \& Corbett, A.C. The duality of internal and external development of successors: Opportunity recognition in family firms, Family Business Review, 2011, 24(2): 111 -125.

[12] Schröder, E., Schmitt-Rodermund, E., \& Arnaud, N. Career choice intentions of adolescents with a family business background, Family Business Review, 2011, 24(4): 305-321.

[13] Sharma, P., Irving, P.G. Four bases of family business successor commitment: antecedents and consequences. Entrepreneurship Theory \& Practice, 2005, 29 (1):13-33.

[14] Stavrou, E.T., Swiercz, P.M. Securing the future of the family enterprise: a model of offspring intentions to join the business. Entrepreneurship Theory \& Practice, 1998, 23 (2): 19-39.

[15] Stavrou E T. Succession in family businesses: exploring the effects of demographic factors on offspring intentions to join and take over the business. Journal of Small Business Management, 1999, 37(3):43-61.

[16] Tan, L. The research on the cultivating situation of the family business successors in Zhejiang Province(In Chinese), Commercial Time, 2008, 24: $111-112$.

[17] The family business research group of Chinese civilian (private) economy seminar, Chinese family business development report(In Chinese), Beijing: Zhongxin Press, 2011.

[18] Van der Merwe, S.P. An investigation into the suitability of younger generation successors in small and medium-sized family businesses, South African Journal of Business Management, 2011, 42(1): 31-44.

[19] Yu, X.Q. The analysis on the factors that influence the family business offspring's succession intention: based on the survey in Wenzhou(In Chinese), Soft Science, 2008, 22(8):55-59.

[20] Zellweger, T., Sieger, P., \& Halter, F. Should I stay or should I go? Career choice intentions of students with family business background, Journal of Business Venturing, 2011, 26: 521-536. 